Bull. Egypt. Soc. Physiol. Sci. Vol. (41) Issue (3), 344-357

\author{
Bull. of Egyp. Soc. Physiol. Sci. \\ (Official Journal of Egyptian Society for Physiological Sciences) \\ (pISSN: 1110-0842; eISSN: 2356-9514)
}

\title{
Potential Mechanisms Underlying the Renoprotective Effect of Empagliflozin, a Novel Selective Sodium Glucose Co-transporter (SGLT) 2 Inhibitor, against Diabetic Nephropathy in Streptozotocin Induced Diabetic Rats
}

\author{
Mona A. Said and Hend A. Abdallah \\ Physiology department, Faculty of Medicine, Benha University, Egypt.
}

Submit Date: Sept 29, 2020

Revise Date: Dec 25, 2020

Available Online: Feb 1,2021

Keywords

SGLT-2 inhibitors

Empagliflozin

Diabetic

nephropathy

\begin{abstract}
Background: Diabetic nephropathy is a major microvascular complication of diabetes and a primary cause of end-stage renal disease worldwide. This study was designed to assess whether control of hyperglycemia with empagliflozin, a new sodium glucose cotransporter (SGLT) 2 inhibitor could improve the renal functions in streptozotocin induced diabetic rats. Thirty two adult male albino rats were randomly assigned into four equal groups. Group I; non diabetic control, Group II; non diabetic rats treated with empagliflozin, group III; diabetic rats and group IV; diabetic rats treated with empagliflozin. Diabetic rats treated with empagliflozin showed significant increase in body weight and significant reduction in Kidney weight, blood glucose and glycated haemoglobin (HbA1c) levels. Empagliflozin also produced significant decrease in blood urea nitrogen (BUN), serum creatinine, urinary albumin excretion (UAE), tumor necrosis factor alpha (TNF- $\alpha$ ), interleukin 6 (IL-6) and transforming growth factor beta-1 (TGF$\beta 1)$. It also attenuated Kidney tissue oxidative stress. Empagliflozin showed a renoprotective effect in streptozotocin induced diabetic rats through its glucose lowering effect and by reducing oxidative stress, inflammation, fibrosis and histopathological alterations. SGLT-2 inhibitor seems to be a promising therapeutic strategy for managing diabetes mellitus to slow the progression of diabetic nephropathy.
\end{abstract}

Corresponding author: Mona A. Said, E.Mail: dr.monaabdelazim@gmail.com, Mobile: $00201117060320 . P h y s i o l o g y$ department, Faculty of Medicine, Benha University, Egypt. 


\section{INTRODUCTION}

Diabetes mellitus (DM) is a major cause of morbidity and mortality worldwide for its micro-vascular and macro-vascular complications [1]. Diabetic nephropathy (DN) is one of the most serious microvascular diabetic complications and the most common cause of end-stage renal failure worldwide. It is also considered as a major indication for dialysis and transplantation. DN accounts for $14 \%$ of all deaths in diabetic patients and for $40 \%$ of end-stage renal cases [2]. It affects about $15 \%-25 \%$ of type I and $30 \%-40 \%$ of type II diabetic patients [3, 4].

DN is characterized by specific renal morphological and functional alterations including glomerular hyperfiltration and hypertrophy, thickening of glomerular basement membrane, expansion of mesangial extracellular matrix and fibrosis that is associated with decline of glomerular filtration rate and substantial proteinuria [5]. DN results from the combined effects of various genetic and environmental factors. Several factors, such as hyperglycemia, hyperlipidemia, oxidative stress and inflammatory cytokines contribute to the progression of renal damage in DN. In spite of the number of studies on rodent and human models of experimental DN, effective therapy is not available yet. Consequently, the search for drugs that prevent the progression of $\mathrm{DN}$ has high priority in biomedical research [6].

In the last decade, researchers have gained more interest in understanding the pathophysiologic mechanisms of diabetes mellitus as a chronic progressive disease. Kidney is one of the main treatment targets in diabetes by increasing glucose reabsorption above normal. This discovery has led to the development of the sodium glucose cotransporter 2 inhibitors (SGLT2) [7] which are specifically expressed in renal proximal tubules in [8] diabetic patients [9] and animals [10]. These agents block glucose reabsorption in the proximal tubules and enhance urinary glucose excretion when the blood glucose level exceeds the renal threshold thereby lower plasma glucose levels [7].

The mechanism of action of the SGLT2 inhibitors is insulin independent that makes them a novel treatment of diabetes [7]. Beyond their antihyperglycemic properties, use of SGLT2 inhibitors was associated with additional nonglycemic benefits including reduction in blood pressure and plasma uric acid in diabetic patients $[11,12]$. Several SGLT2 inhibitors are now being developed in clinical studies. However, to date, the results examining their renoprotective effects in both clinical studies and animal models of diabetic nephropathy are not consistent so it remains to be determined whether the potential long-term effect of these agents in controlling hyperglycemia will prevent the development and progression of diabetic nephropathy $[13,14]$.

Empagliflozin, (trade name Jardiance), is a novel inhibitor of the sodium glucose cotransporter-2 (SGLT-2), a drug of the gliflozin class, approved for the treatment of type 2 diabetes in adults in 2014 [15]. It is highly selective and potent inhibitor of SGLT2, compared with other SGLT2 inhibitors [16]. In the present experimental study, we hypothesized that whether short term glycemic control with empagliflozin can 
ameliorate diabetic nephropathy in rats focusing on the mechanisms underlying its possible renoprotective effects.

\section{Materials and Method:}

\subsection{Chemicals:}

Empagliflozin [BI 10773; 1-chloro-4-

( $\beta$-D-glucopyranos-1yl)-2-(4-[(S)-

tetrahydrofuran-3-yl-oxy]-benzyl)-benzene]

was purchased from (Boehringer Ingelheim

Pharma GmbH \& Co.KG, Germany).

Streptozotocin powder was provided by (Sigma

Aldrich, St. Louis, MO, USA).

\subsection{Animals:}

Thirty two male Albino Wistar rats, 8 10 weeks old and weighing between $200-250 \mathrm{~g}$ were purchased from the animal house of faculty of medicine, Cairo University, Egypt. The animals were kept in cages with free access to both water and standard rat chow (El-Nasr Company, Cairo, Egypt) under controlled temperature $\left(22-24^{\circ} \mathrm{C}\right)$, humidity (40-60\%) and light-dark cycle (12-12 h). Experiments were conducted in accordance with the guide for the care and use of laboratory animals and efforts were made to minimize the animals' suffering. All procedures were approved by the Institutional Ethical Committee for Animal Care and Use of the Faculty of Medicine, Benha University. After 2 weeks acclimatization period, the animals were randomly assigned into four equal groups ( $\mathrm{n}=8$ rats per each group):

Group I (Non diabetic control group): normal rats given free access to food and water.

Group II (Non diabetic treated group): rats were treated with empagliflozin $(3 \mathrm{mg} / \mathrm{kg} /$ day $)$ by oral gavage once daily for 5 weeks [17].
Group III (Diabetic non treated group): streptozotocin induced diabetic rats.

Group IV (Diabetic treated group): diabetic rats treated with empagliflozin ( $3 \mathrm{mg} / \mathrm{kg} /$ day) by oral gavage once daily for 5 weeks [17].

\subsection{Induction of type 2 diabetes}

After an overnight fasting, diabetes was induced in rats by intraperitoneal (i.p.) injection of nicotinamide $(230 \mathrm{mg} / \mathrm{kg}), 15 \mathrm{~min}$ prior to the i.p. injection of single dose of streptozotocin (60 $\mathrm{mg} / \mathrm{kg}$ ) diluted in $0.1 \mathrm{M}$ cold sodium citrate buffer ( $\mathrm{pH} 4.5)$ [18]. Control rats received equal volumes of the vehicles alone. Blood glucose level was measured from tail vein blood 48 hours later using Glucotrend 2 glucometer. Rats with moderate hyperglycemia (non-fasting blood glucose $\geq 250$ $\mathrm{mg} / \mathrm{dl}$ ) were considered diabetic and included in the study which lasted for five weeks after induction of diabetes [19].

\subsection{Blood and tissue sampling}

By the end of the experimental period and after an overnight fast, rats of all experimental groups were weighed then they were anesthetized with pentobarbital (50 mg/kg i.p.). Blood samples were obtained from abdominal aorta, collected in capillary tubes and were allowed to clot at room temperature. The sera were separated by centrifugation at $3000 \mathrm{rpm}$ for $15 \mathrm{~min}$ and stored at - $80^{\circ} \mathrm{C}$ for biochemical assessment of blood glucose, Glycosylated Hemoglobin (HbA1c), Blood Urea Nitrogen (BUN), serum creatinine, TNF- $\alpha$, IL- 6 and TGF- $\beta 1$. The right kidney was rapidly removed, weighed, washed with ice-cold $0.9 \%$ saline solution, and processed for biochemical analysis of tissue oxidative status while left kidneys were removed, weighed and processed for histopathological examination. 


\subsection{Collection of 24-hour urine}

The collected urine for 24 hours was measured and then centrifuged for $5 \mathrm{~min}$ at $1500 \mathrm{rpm}$ and the clear supernatant was stored at $-20^{\circ} \mathrm{C}$. Urinary albumin was measured by means of quantitative reaction using diagnostic commercial kits (Sigma Aldrich, St. Louis, MO, USA). Urinary Albumin Excretion (UAE) rate (mg/24 hours) was determined according to Bradford method [20].

2.6. Assessment of blood glucose and glycosylated hemoglobin (HbA1c)

Fasting blood glucose levels were determined by enzymatic method according to Trinder [21] using glucose kits (Spinreact, SA, Ctra Santa Cloma, Spain). Glycosylated hemoglobin (HbA1c) levels were assayed according to the method of Nayak and Pattabiraman [22].

\subsection{Assessment of renal function}

The BUN concentrations and serum creatinine levels were measured by an enzymatic assay method using commercial kits (Roche Diagnostics GmbH, Germany).

2.8. Assessment of serum tumor necrosis factor alpha (TNF- $\alpha$ ), interlekin -6 (IL-6) and transforming growth factor beta (TGF- $\beta 1)$ :

Serum levels of TNF- $\alpha$, IL- 6 and TGF- $\beta 1$ were measured using commercially available ELISA kits following the manufacturer's guidelines (R\&D Systems, Minneapolis, MN, USA).

\subsection{Assessment of tissue oxidative status}

The renal cortex of the right kidney was separated, kept frozen in liquid nitrogen at $-80^{\circ} \mathrm{C}$. Then, it was homogenized in cold potassium phosphate buffer (PH 7.4). The homogenates were centrifuged at $5000 \mathrm{rpm}$ for $10 \mathrm{~min}$ at $4{ }^{\circ} \mathrm{C}$ and the supernatant fraction is used for further analyses of malondialdehyde (MDA), superoxide dismutase (SOD) and reduced glutathione (GSH) using commercial kits (Randox Laboratories, Barcelona, Spain) following the manufacturer's guidelines [23, 24].

\subsection{Hisopathological examination}

Left kidneys were fixed in $10 \%$ formalin solution, dehydrated and embedded in paraffin. Tissue sections of $5 \mu \mathrm{m}$ thick were taken stained with Hematoxylin and Eosin (H-E). Samples were examined under light microscope. The glomerular matrix expansion index was scored in four levels from 0 to 4 , as follows: 0 , normal glomeruli; 1 , matrix expansion occurred in up to $25 \%$ of a glomerulus; 2, matrix expansion occurred in $25-$ $50 \%$ of a glomerulus; 3, matrix expansion occurred in $50-75 \%$ of a glomerulus; and 4 , matrix expansion occurred in $75-100 \%$ of a glomerulus [25].

\subsection{Statistical analysis.}

All analyses were performed using the program Statistical Package for Social Sciences version 19 (SPSS Inc, Chicago, IL, USA). The data are presented as the mean \pm standard deviation (SD). Comparisons between groups were analyzed by using one-way Analysis of Variance (ANOVA) and Bonferroni's Multiple Comparison Test. Probability of chance $(P$ value $)<0.05$ was considered statistically significant.

\section{Results :}

\subsection{Effect of empagliflozin on body weight,} kidney weight, serum glucose and HbA1c (Table 1) 
Non-significant change in body weight, kidney weight, serum glucose and HbAlc was observed in non diabetic rats treated with empagliflozin, compared with the control group $(P>0.05)$. Induction of type 2 diabetes produced significant decrease in body weight and significant increases in kidney weight, blood glucose and $\mathrm{HbAlc}$ as compared with control group $(P<0.05)$. Diabetic rats treated with empagliflozin showed significant increase in body weight $(P<0.05)$ and significant reduction in Kidney weight, blood glucose and $\mathrm{HbA} 1 \mathrm{c}$ levels when compared with diabetic non-treated group $(P<0.05)$.

\subsection{Effect of empagliflozin on kidney function parameters (Table 2)}

There was non-significant change in BUN, serum creatinine and UAE in nondiabetic rats treated with empagliflozin, compared with the control group $(P>0.05)$. BUN and serum creatinine were significantly increased in diabetic rats as compared with control group $(P<0.05)$. Treatment with empagliflozin produced a significant reduction in their levels as compared with diabetic nontreated group $(P<0.05)$. Assessment of albuminuria, a characteristic feature of diabetic nephropathy reflected by albumin excretion rate, showed significant increase in diabetic group compared with normal control group ( $P$ $<0.05)$. Treatment with empagliflozin leads to significant reduction in UAE, compared with diabetic non-treated rats $(P<0.05)$.

\subsection{Effect of emapagliflozin on inflammatory} markers (Table 3)

There was non-significant change in TNF-a, IL-6 and TGF- $\beta 1$ in non-diabetic rats treated with empagliflozin, compared with the control group $(P>0.05)$. TNF-a, IL-6 and TGF- $\beta 1$ were significantly higher in diabetic rats as compared with control group $(P<0.05)$. Treatment with empagliflozin significantly lowered their levels as compared with diabetic non treated rats $(P<0.05)$.

\subsection{Effect of emapagliflozin on kidney tissue oxidative stress (Table 4)}

MDA content of the renal tissue was found to be non-significantly changed in non diabetic rats treated with empagliflozin compared to normal control group $(P>0.05)$ while it was significantly increased in diabetic non treated group compared to the control group $(P<0.05)$. Moreover, diabetic group treated with empagliflozin, significantly decreased the elevation in renal MDA level as compared to diabetic non treated group $(P<$ 0.05). As regards the antioxidant enzyme activity, the renal tissue SOD and GSH contents were non significantly changed in non diabetic rats treated with empagliflozin compared to normal control group $(P>0.05)$ while they were significantly decreased in diabetic non treated group compared to the control group $(P<0.05)$. Furthermore, diabetic group treated with empagliflozin, significantly increased renal SOD and GSH contents as compared to diabetic non treated group $(P<$ $0.05)$. 
3.1. Effect of empagliflozin on Body weight, mean kidney weight, blood glucose level and HbA1c (Table 1).

\begin{tabular}{|c|c|c|c|c|}
\hline Groups & \multirow{2}{*}{$\begin{array}{c}\text { Group I } \\
\text { (Control) }\end{array}$} & $\begin{array}{c}\text { Group II } \\
\text { (Non diabetic }+ \\
\text { Empagliflozin) }\end{array}$ & $\begin{array}{c}\text { Group III } \\
\text { (Diabetic) }\end{array}$ & $\begin{array}{c}\text { Group IV } \\
\text { (Diabetic }+ \\
\text { Empagliflozin) }\end{array}$ \\
\hline Body weight (gram) & $258.31 \pm 1.29$ & $257.12 \pm 1.96$ & $198.85 \pm 1.13^{*}$ & $237.17 \pm 1.19^{\dagger}$ \\
\hline Mean kidney weight (mg) & $621.68 \pm 8.62$ & $616.39 \pm 7.49$ & $677.75 \pm 6.86^{*}$ & $635.08 \pm 7.75^{\dagger}$ \\
\hline Blood glucose (mg/dl) & $97.90 \pm 7.40$ & $95.44 \pm 6.16$ & $297.82 \pm 11.64^{*}$ & $160.59 \pm 8.34^{\dagger}$ \\
\hline Glycosylated HbA1c (\%) & $3.03 \pm 0.05$ & $2.99 \pm 0.03$ & $5.96 \pm 0.05^{*}$ & $3.18 \pm 0.13^{\dagger}$ \\
\hline
\end{tabular}

Data is expressed as mean \pm standard deviation, $P$. value $=$ probability of chance, $P<0.05$ is significant tested by using One-way analysis of variance (ANOVA) test and Bonferroni's Multiple Comparison Test.

"Significant difference $v s$ the control group

$\dagger$ Significant difference $v s$ the diabetic group.

\subsection{Effect of empagliflozin on renal function parameter (Table 2).}

\begin{tabular}{|c|c|c|c|c|}
\hline Groups & $\begin{array}{c}\text { Group I } \\
\text { (Control) }\end{array}$ & $\begin{array}{c}\text { Group II } \\
\text { (Non diabetic }+ \\
\text { Empagliflozin) }\end{array}$ & $\begin{array}{c}\text { Group III } \\
\text { (Diabetic) }\end{array}$ & $\begin{array}{c}\text { Group IV } \\
\text { (Diabetic }+ \\
\text { Empagliflozin) }\end{array}$ \\
\hline Serum creatinine (mg/dl) & $0.25 \pm 0.02$ & $0.27 \pm 0.01$ & $1.81 \pm 0.09^{*}$ & $0.51 \pm 0.04^{\dagger}$ \\
\hline BUN (mg/d) & $28.12 \pm 1.18$ & $27.23 \pm 1.13$ & $58.62 \pm 3.21^{*}$ & $30.54 \pm 1.78^{\dagger}$ \\
\hline UAE (mg/24h) & $0.44 \pm 0.05$ & $0.45 \pm 0.13$ & $3.75 \pm 0.21^{*}$ & $0.62 \pm 0.11^{\dagger}$ \\
\hline
\end{tabular}

Data is expressed as mean \pm standard deviation, $P$. value $=$ probability of chance, $P<0.05$ is significant tested by using One-way analysis of variance (ANOVA) test and Bonferroni's Multiple Comparison Test.

*Significant difference $v s$ the control group

$\uparrow$ Significant difference $v s$ the diabetic group.

3.3. Effect of empagliflozin on serum level of inflammatory and fibrotic markers (Table 3).

\begin{tabular}{|c|c|c|c|c|}
\hline Groups & \multirow{2}{*}{$\begin{array}{c}\text { Group I } \\
\text { (Control) }\end{array}$} & $\begin{array}{c}\text { Group II } \\
\text { (Non diabetic }+ \\
\text { Empagliflozin) }\end{array}$ & $\begin{array}{c}\text { Group III } \\
\text { (Diabetic) }\end{array}$ & $\begin{array}{c}\text { Group IV } \\
\text { (Diabetic }+ \\
\text { Empagliflozin) }\end{array}$ \\
\hline TNF-a (Pg/ml) & $46.68 \pm 1.30$ & $47.30 \pm 1.48$ & $138.81 \pm 9.40^{*}$ & $63.88 \pm 4.99^{\dagger}$ \\
\hline IL-6 (Pg/ml) & $65.75 \pm 0.88$ & $67.11 \pm 0.87$ & $126.80 \pm 0.77^{*}$ & $70.14 \pm 0.65^{\dagger}$ \\
\hline TGF- $\mathbf{\beta 1} \mathbf{( n g / m l )}$ & $5.89 \pm 0.42$ & $6.15 \pm 0.41$ & $18.54 \pm 1.23^{*}$ & $7.13 \pm 1.18^{\dagger}$ \\
\hline
\end{tabular}

Data is expressed as mean \pm standard deviation, $P$. value $=$ probability of chance, $P<0.05$ is significant tested by using One-way analysis of variance (ANOVA) test and Bonferroni's Multiple Comparison Test *Significant difference vs the control group

$\dagger$ Significant difference $v s$ the diabetic group.

\subsection{Effect of empagliflozin on levels of histopathological grading, kidney lipid peroxidation and antioxidants} (Table 4)

\begin{tabular}{|c|c|c|c|c|}
\hline Groups & \multirow{2}{*}{$\begin{array}{c}\text { Group I } \\
\text { (Control) }\end{array}$} & $\begin{array}{c}\text { Group II } \\
\text { (Non diabetic }+ \\
\text { Empagliflozin) }\end{array}$ & $\begin{array}{c}\text { Group III } \\
\text { (Diabetic) }\end{array}$ & $\begin{array}{c}\text { Group IV } \\
\text { (Diabetic }+ \\
\text { Empagliflozin) }\end{array}$ \\
\hline Histopathological grading & 0 & 0 & $3.13 \pm 0.01^{*}$ & $0.51 \pm 0.02^{\dagger}$ \\
\hline MDA (nmol/mg protein) & $0.26 \pm 0.03$ & $0.27 \pm 0.01$ & $0.66 \pm 0.05^{*}$ & $0.30 \pm 0.04^{\dagger}$ \\
\hline SOD (U/mg protein) & $6.80 \pm 0.13$ & $6.23 \pm 0.05$ & $2.55 \pm 0.02^{*}$ & $5.73 \pm 0.16^{\dagger}$ \\
\hline GSH ( $\boldsymbol{\mu m o l} / \mathbf{g}$ protein) & $1.41 \pm 0.02$ & $1.67 \pm 0.04$ & $0.49 \pm 0.07^{*}$ & $1.17 \pm 0.04^{\dagger}$ \\
\hline
\end{tabular}

Data is expressed as mean \pm standard deviation, $P$. value $=$ probability of chance, $P<0.05$ is significant tested by using One-way analysis of variance (ANOVA) test and Bonferroni's Multiple Comparison Test.

*Significant difference $v s$ the control group

$\uparrow$ Significant difference $v s$ the diabetic group. 


\subsection{Effect of emapagliflozin on kidney hisopathology (Fig.1)}

Light microscopical photomicrograph of renal tissues from both non-diabetic control rats (Figure 1A) and non-diabetic rats treated with empagliflozin (Figure 1B) showed normal glomerular capillary wall thickness and texture. In addition, no mesangial expansion, mesangial hypercellularity, nodular glomerulosclerosis, capsular drop or hyaline thrombi were observed. On the other hand, in the diabetic non treated group (Figure 1C), the rats showed shrinking of the glomerular tufts, thickening of basement membrane, increase of Bowman's space and dilations of kidney tubules. In contrast, treatment with empagliflozin significantly improved the renal lesions in diabetic rats (Figure 1D).

\subsection{Effect of empagliflozin on kidney histopathological examination (Fig. 1)}
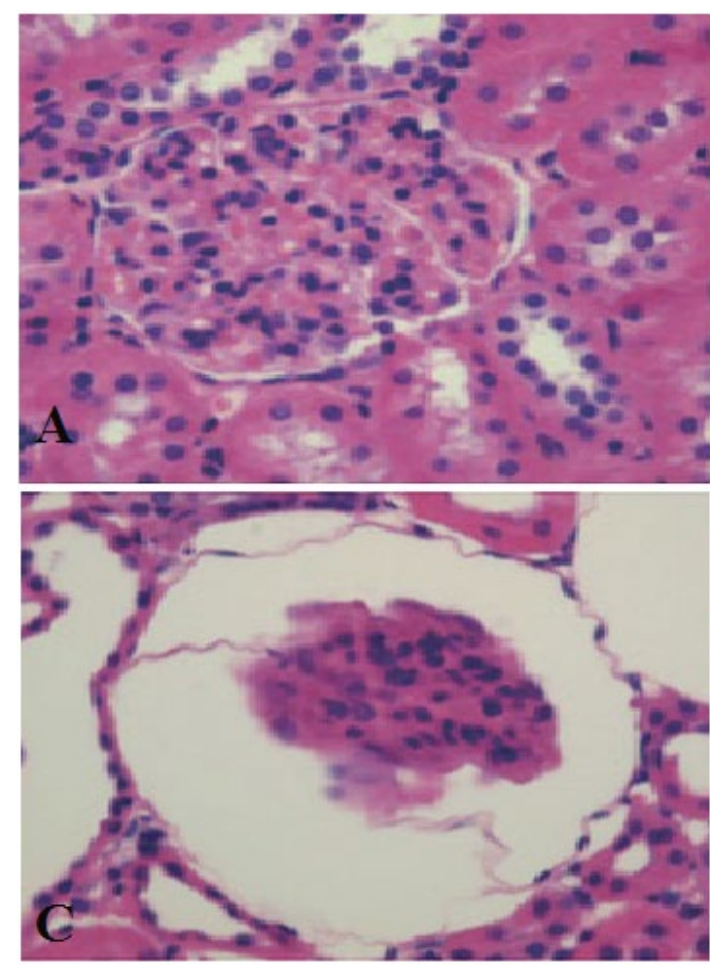

\section{Discussion}

Diabetic nephropathy (DN) is one of the most dangerous microvascular diabetic complications and the most common cause of end-stage renal disease with serious gradual decline in renal function [2]. Diabetic nephropathy is characterized functionally by albuminuria and proteinuria and pathologically by glomerular hypertrophy, mesangial expansion and tubulointerstitial fibrosis [26].

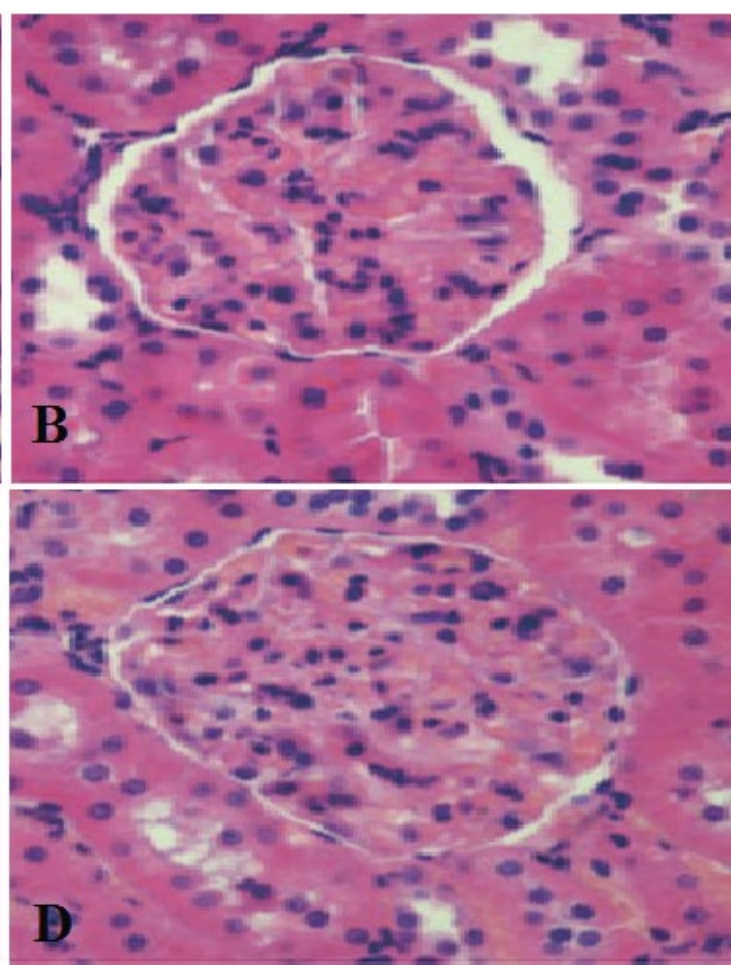

The exact pathogenic mechanism involved in the induction and progression of diabetic nephropathy is still remaining controversial. However, hyperglycemia is the main pathological characteristics of type $2 \mathrm{DM}$ and the key initiating factors involved in the progression of DN [27]. Increased levels glucose in kidney can directly stimulate oxidative stress, inflammation and fibrosis in both renal glomeruli and tubules [28, 29]. However, to date, the current available 
therapies only slow, not prevent, the development of renal disease. Thus, there is a need to explore more therapies that might be more renal protective [27].

Several new SGLT2 inhibitors, that block glucose reabsorption in the proximal tubule, have been developed for the treatment of diabetes mellitus. One of the compounds in this class is empagliflozin [15]. However, to date, the potential renoprotective effects of empagliflozin on progression of diabetic nephropathy in animal models of diabetes have not been completely elucidated. Thus, the aim of the present study was to investigate the protective effects of short term treatment with empagliflozin, against diabetic renal damage in rat model of type 2 diabetes mellitus and the possible underlying mechanism.

The current study demonstrated decrease in body weight in diabetic rat when compared with the control group which is in agreement with previous studies [29, 30, 31]. This loss in body weight has been found to be related with muscle loss as a result of over catabolism of tissue proteins due to unavailability of carbohydrate to be utilized as an energy source [32]. This was in contrast to Abdel-Wahab et al. 2016 who found nonsignificant difference in body weight in diabetic rats compared to control rats [19]. Diabetic rats treated with empagliflozin showed significant increase in body weight as compared with diabetic non-treated rats by controlling blood glucose level thereby preventing protein catabolism which is in agreement to the previous studies [33, 34]. As regard kidney weight, induction of diabetes resulted in significant increase in kidney weight which may reflect renal inflammatory process in diabetic rats. This is in congruent with other studies [30, 35] but in contrary to other results which found significant decrease [36] or nonsignificant difference in kidney weight in diabetic rats compared with control rats [37]. Treatment of diabetic rats with empagliflozin significantly reduced kidney weight as compared with the diabetic non treated rats. This may explain decreased inflammatory process in the kidney of diabetic rats.

In the present study, induction of diabetes in rats led to significant increase in blood glucose level and glycosylated hemoglobin associated with significant impairment of renal function manifested by significant increase in serum creatinine, blood urea nitrogen and urinary albumin excretion with is convenient to previous studies [19, 30, 34]. This impairment was ameliorated in diabetic rats treated with SGLT-2 inhibitor, empagliflozin. Empagliflozin was found to reduce hyperglycemia in patients with type II diabetes through reducing the renal reabsorption of glucose, thereby increasing urinary glucose excretion $[34,38]$. The use of empagliflozin has been associated with lowered level of glycosylated hemoglobin in patients with type 2 diabetes, including those with chronic kidney disease [39]. Empagliflozin was found to reduce some of the early features of diabetic nephropathy as glomerular hypertrophy and glomerular matrix expansion in type 2 diabetic animals [40]. The mechanisms behind the renal effects of empagliflozin are multiple and complex. However, direct renovascular effects may play an important role [41]. Empagliflozin was shown to improve 
glucose homeostasis in type I diabetes mellitus which are probably due to reduction of apoptosis and reactive oxygen species in pancreatic $\beta$ - cells [42]. Empagliflozin reduces sodium reabsorption in proximal tubular, thus increasing distal sodium delivery to the macula densa, which activates tubuloglomerular feedback, leading to afferent vasomodulation and a decrease in hyperfiltration [43]. Empagliflozin has been shown to reduce intraglomerular pressure, glomerular filtration rate (GFR) and improve hyperfiltration in patients with type I diabetes. These effects may translate into improved renal outcomes [44].

In the current study, diabetic non-treated rats led to a significant increase in the inflammatory cytokine, TNF- $\alpha$ and IL-6 in addition to the fibrotic cytokine, TGF- $\beta 1$ as compared to the control rats. TNF- $\alpha$, interleukins and TGF- $\beta 1$ have been recognized as important factors contributing to the development of diabetes and their expression are increased in diabetic renal tissue $[45,46]$. In diabetic kidney, macrophages accumulation and activation is associated with glomerular immune complex deposition, increased cytokine production, and progressive fibrosis [47]. Current results also showed that treatment with empagliflozin, produced significant reduction in the elevated levels of TNF- $\alpha$, IL- 6 and TGF- $\beta 1$. This is in agreement to Gallo et al. 2016 who postulated that empagliflozin in diabetic mice improved glycemic control and reduced collagen accumulation and renal expression of TGF $\beta 1$ meanwhile, it failed to reduce albuminuria, urinary kidney injury molecule 1 (KIM-1) or glomerulosclerosis [48].

The current study also revealed a significant increase in the renal MDA levels in addition to decreased antioxidant enzymes, GSH and SOD in diabetic rats compared with control animals. Several studies have demonstrated the importance of oxidative stress in the pathogenesis of diabetic nephropathy $[49,50]$. MDA level was increased in plasma [51] and renal cortex of STZinduced diabetic animals [52]. Alterations in the redox state in $\mathrm{DN}$, caused by a state of hyperglycemia, and the increase in advanced glycation end products (AGEs) affects transforming growth factor-beta (TGF- $\beta$ ) signaling, producing chronic inflammation and glomerular and tubular hypertrophy and favoring the appearance of oxidative stress [53]. The kidney of diabetic rats treated with empagliflozin showed lower MDA levels and higher activities of antioxidant enzymes, GSH and SOD. This is in agreement with Oelze et al. [54] who found that empagliflozin improves hyperglycemia and prevents the development of oxidative stress in type 1 diabetic rats.

\section{Conclusion}

Current results demonstrated that empagliflozin improved the kidney function and slowed progression of diabetic nephropathy in a rat model of streptozotocin induced diabetes through its glucose lowering effect and by its antiinflammatory, antifibrotic and anti-oxidant effects thus GLUT-2 inhibitor seems to be a promising therapeutic strategy for managing diabetes mellitus to slow the progression of diabetic nephropathy. However, more experimental and clinical trials are recommended to explore the benefits of SGLT-2 inhibitors in prevention of diabetic macrovascular and microvascular complications as well as to find out more mechanisms of action. 


\section{Conflict of interest}

The authors declare that there is no conflict of interest.

\section{References}

1. Golden, S.H. Emerging therapeutic approaches for the management of diabetes mellitus and macrovascular complications. Am. J. Cardiol. 2011; 108(3 Suppl): 59B - 67B. doi: 10.1016/j.amjcard.2011.03.017.

2. Lasaridis, A.N., Sarafidis P.A. Diabetic nephropathy and anti hypertensive treatment, what are the lessons from clinical trials? Am. J. Hypertens. 2003; 16(8): 689 - 97. doi: https://doi.org/10.1016/S0895-7061(03)008641

3. Hovind, P., Tarnow, L., Rossing, K., Rossing, P., Eising, S., Larsen, N., Binder, C., Parving H.H., Decreasing incidence of severe diabetic microangiopathy in type 1 diabetes. Diabetes Care. 2003; 26(4):1258 1264. doi: 10.2337/diacare.26.4.1258.

4. Yokoyama, H., Okudaira, M. Otani T., Sato, A., Miura, J., Takaike, H., Yamada, H., Muto, K., Uchigata, Y., Ohashi, Y., Iwamoto, Y. Higher incidence of diabetic nephropathy in type 2 than in type 1 diabetes in early-onset diabetes in Japan," Kidney International. 2000; 58(1): 302 - 311. doi:10.1046/j.15231755.2000.00166.x.

5. Wolf G. New insights into the pathophysiology of diabetic nephropathy: from haemodynamics to molecular pathology. Eur. J. Clin. Invest. 2004; 34: 785 - 96. doi: 10.1111/j.13652362.2004.01429.x

6. Shah, I.M., Mackay, S.P., McKay, G.A. Therapeutic strategies in the treatment of diabetic nephropathy-a translational medicine approach. Curr. Med. Chem. 2009; 16(8): 997 1016. doi: 10.2174/092986709787581897.

7. Shubrook, J.H., Bokaie, B.B., Adkins, S.E. Empagliflozin in the treatment of type 2 diabetes: evidence to date. Drug Des. Devel. Ther. 2015; 9: 5793 - 803. doi: 10.2147/DDDT.S69926.

8. Wright, E.M., Loo, D.D., Hirayama, B.A. Biology of human sodium glucose transporters. Physiol. Rev. 2011; 91(2): 733 - 794. doi: 10.1152/physrev.00055.2009.

9. Rahmoune, H., Thompson, P.W., Ward, J.M., Smith, C.D., Hong, G., Brown, J. Glucose transporters in human renal proximal tubular cells isolated from the urine of patients with non-insulin-dependent diabetes. Diabetes. 2005; 54(12): 3427 - 3434. doi: 10.2337/diabetes.54.12.3427.

10. Tabatabai, N.M., Sharma, M., Blumenthal, S.S., Petering, D.H. Enhanced expressions of sodium-glucose cotransporters in the kidneys of diabetic Zucker rats. Diabetes Res. Clin. Pract. 2009; 83(1): e27 - e30. doi: 10.1016/j.diabres.2008.11.003.

11.Chino, Y., Samukawa, Y., Sakai, S., Nakai, Y., Yamaguchi, J.I., Nakanishi, T., Tamai, I. SGLT-2 inhibitor lowers serum uric acid through alteration of uric acid transport activity in renal tubule by increased glycosuria. Biopharm. Drug Dispos. 2014; 35(7): 391 404. doi: 10.1002/bdd.1909.

12. Oliva, R.V., Bakris, G.L. Blood pressure effects of sodium-glucose co-transport 2 (SGLT2) inhibitors. J. Am. Soc. Hypertens. 2014; 8(5): $330 \quad$ - 339. doi: 10.1016/j.jash.2014.02.003. 
13. Chao, E.C., Henry, R.R. SGLT2 inhibition a novel strategy for diabetes treatment. Nat. Rev. Drug Discov. 2010; 9(7): 551 - 559. doi: 10.1038/nrd3180.

14. Ferrannini, E., Solini, A. SGLT2 inhibition in diabetes mellitus: rationale and clinical prospects. Nat. Rev. Endocrinol. 2012; 8(8): 495 - 502. doi: 10.1038/nrendo.2011.243.

15. Scheen, A.J. [Empagliflozin (Jardiance): nw SGLT2 cotransporter inhibitor for treating type 2 diabetes]. Rev. Med. Liege. 2015; 70(9): 472 - 9. PMID: 26638450.

16. Liakos, A., Karagiannis, T., Athanasiadou, E., Sarigianni, M., Mainou, M., Papatheodorou, K., Bekiari, E., Tsapas, A. Efficacy and safety of empagliflozin for type 2 diabetes: a systematic review and metaanalysis. Diabetes Obes. Metab. 2014, 16: 984 -993. doi: 10.1111/dom.12307.

17. Thomas, L., Grempler, R., Eckhardt, M., Himmelsbach, F., Sauer, A., Klein, T., Eickelmann, P., Mark, M. Long-term treatment with empagliflozin, a novel, potent and selective SGLT-2 inhibitor, improves glycaemic control and features of metabolic syndrome in diabetic rats. Diabetes Obes. Metab. 2012; 14(1): 94 - 6 . doi: 10.1111/j.1463-1326.2011.01518.x.

18. Masiello, P., Broca, C., Gross, R., Roye, M., Manteghetti, M., Hillaire-Buys, D., Novelli, M., Ribes, G. Experimental NIDDM: development of a new model in adult rats administered streptozotocin and nicotinamide. Diabetes. 1998; 47: 224 - 229. doi: 10.2337/diab.47.2.224.

19. Abdel-Wahab, A.F., Mahmoud, W., AlHarizy, R. Comparative Renal Protective
Effects of Canagliflozin and Telmisartan in a Rat Model of Diabetic Nephropathy. J. Nephrol. Renal Ther. 2016; 2: 010. doi:10.24966/NRT-7313/100010.

20. Bradford, M.M. A rapid and sensitive method for the quantitation of microgram quantities of protein utilizing the principle of protein-dye binding. Anal. Biochem. 1976; 72: 248 - 254. https://www.sciencedirect.com/science/article/a bs/pii/0003269776905273.

21. Trinder P. Determination of Glucose in Blood Using Glucose Oxidase with an Alternative Oxygen Acceptor. Ann. Clin. Biochem. 1969; 6: 24

27. https://doi.org/10.1177/000456326900600108.

22. Nayak, S.S., Pattabiraman, T.N. A new colorimetric method for the estimation of glycosylated hemoglobin. Clin. Chim. Acta. 1981; $109(3): \quad 267 \quad-\quad 274$. https://doi.org/10.1177/000456326900600108

23.Uchiyama, M., Mihara, M. Determination of malondialdehyde precursor in tissues by thiobarbituric acid test. Anal Biochem; 1978; 86:271-278. https://doi.org/10.1016/00032697(78)90342-1

24.Das, S., Vasishat, S., Das, S.N., Srivastava, L.M. Correlation between total antioxidant status and lipid peroxidation in hypercholesterolemia. Curr. Sci. 2000; 78(4): $486-487$.

25.Tzeng, T., Liou, S., Chang, C.J., Liu, I. Zerumbone, a tropical ginger sesquiterpene, ameliorates streptozotocin-induced diabetic nephropathy in ratsby reducing the hyperglycemia-induced inflammatory response. Nut. Metabol. 2013; 10: 64. doi: 10.1186/17437075-10-64. 
26.Ueda, H., Ishimura, E., Shoji, T. Emoto, M., Morioka, T., Matsumoto, N., Fukumoto, S., Miki, T., Inaba, M., Nishizawa, Y. Factors affecting progression of renal failure in patients with type 2 diabetes. Diabetes Care. 2003; 26(5): $1530 \quad$ - $\quad 1534 . \quad$ doi: 10.2337/diacare.26.5.1530.

27. Balakumar, P., Arora, M.K., Reddy, J., Anand-Srivastava, M.B. Pathophysiology of diabetic nephropathy: involvement of multifaceted signalling mechanism. J. Cardiovasc. Pharmacol. 2009; 54(2):129 - 38. doi: 10.1097/FJC.0b013e3181ad2190.

28. Mavridis, G., Souliou, E., Diza, E., Symeonidis, G., Pastore, F., Vassiliou, A.M., Karamitsos, D. Inflammatory cytokines in insulin-treated patients with type 2 diabetes. Nutr. Metab. Cardiovasc. Dis. 2008; 18(7): 471 -6. doi:10.1016/j.numecd.2007.02.013.

29. Rösen, P., Nawroth, P.P., King, G., Möller, W., Tritschler, H.J., Packer, L. The role of oxidative stress in the onset and progression of diabetes and its complications: a summary of a Congress Series sponsored by UNESCOMCBN, the American Diabetes Association and the German Diabetes Society. Diabetes Metab. Res. Rev. 2001; 17(3):189 - 212. doi: 10.1002/dmrr.196.

30. Selvam M., Kaliyaperumal M. Protective effects of naringenin on streptozotocin-induced diabetic nephropathy in rats. Asian Journal of Phytomedicine and Clinical Research. 2015; 3(2): $37-45$.

31. Gajdosík, A., Gajdosíková, A., Stefek, M., Navarová, J., Hozová, R. Streptozotocininduced experimental diabetes in male Wistar rats. Gen Physiol Biophys. 1999; 18: $54-62$. PMID: 10703720.

32. Andallu, B., Varadacharyulu, N.C. Antioxidant role of mulberry (Morusindica L. cv. Anantha) leaves in streptozotocin-diabetic rats. Clin. Chim. Acta. 2003; 338: 3 - 10. doi: 10.1016/s0009-8981(03)00322-x.

33. Vickers, S.P., Cheetham, S.C., Headland, K.R., Dickinson, K., Grempler, R., Mayoux, E., Mark, M., Klein, T. Combination of the sodium-glucose cotransporter-2 inhibitor empagliflozin with orlistat or sibutramine further improves the body-weight reduction and glucose homeostasis of obese rats fed a cafeteria diet. Diabetes Metab. Syndr. Obes. 2014; 7: 265 - 75. doi: 10.2147/DMSO.S58786.

34. Neumiller, J.J. Empagliflozin: a new sodiumglucose co-transporter 2 (SGLT2) inhibitor for the treatment of type 2 diabetes. Drugs Context. 2014; 3: 212262. doi: 10.7573/dic.212262.

35. Garman, J.H., Mulroney, S., Manigrasso, M., Flynn, E., Maric, C. Omega-3-fatty acid rich diet prevents diabetic renal disease. Am. J. Physiol. Renal Physiol. 2009; 296(2): F306 316. doi: 10.1152/ajprenal.90326.2008.

36. Coldiron, A.D., Sanders, R.A., Watkins, J.B. $3^{\text {rd }}$ Effects of combined quercetin and coenzyme Q10 treatment on oxidative stress in normal and diabetic rats. J. Biochem. Mol. Toxicol. 2002; 16(4), $197 \quad-202$. doi:10.1002/jbt. 10035.

37. Teoh, S.L., Latiff, A. and Das, S. Histological changes in the kidneys of experimental diabetic rats fed with Momordicacharantia (bitter gourd) extract. 
Rom. J. Morphol. Embryol. 2010; 51(1): 91 95. PMID: 20191126.

38. Heise, T., Seewaldt-Becker, E., Macha, S., Hantel, S., Pinnetti, S., Seman, L., Woerle, H.J. Safety, tolerability, pharmacokinetics and pharmacodynamics following 4 weeks' treatment with empagliflozin once daily in patients with type 2 diabetes. Diabetes Obes.Metab. 2013; 15(7):613 - 621. doi: 10.1111/dom.12073.

39. Barnett, A.H., Mithal, A., Manassie, J., Jones, R., Rattunde, H.,Woerle, H.J., Broedl, U.C.; EMPA-REG RENAL trial investigators. Efficacy and safety of empagliflozin added to existing antidiabetes treatment in patients with type 2 diabetes and chronic kidney disease: a randomised, double-blind, placebo-controlled trial. Lancet Diabetes Endocrinol. 2014; 2(5): 369 - 384. doi: 10.1016/S2213-8587(13)702080.

40. Gembardt, F., Bartaun, C., Jarzebska, N., Mayoux, E., Todorov, V.T., Hohenstein, B., Hugo, C. The SGLT2 inhibitor empagliflozin ameliorates early features of diabetic nephropathy in BTBR ob/ob type 2 diabetic mice with and without hypertension. Am. J. Physiol. Renal Physiol. 2014; 307(3): F317 25. doi: 10.1152/ajprenal.00145.2014.

41. Wanner, C., Inzucchi, S.E., Lachin, J.M., Fitchett, D., von Eynatten, M., Mattheus, M., Johansen, O.E., Woerle, H.J., Broedl, U.C., Zinman, B.; EMPA-REG OUTCOME Investigators. Empagliflozin and Progression of Kidney Disease in Type 2 Diabetes. N. Engl. J. Med. 2016; 375(4): 323 - 34. doi: 10.1056/NEJMoa1515920.
42. Cheng, S.T.W, Chen, L., Yu, S., Li, T., Mayoux, E., Leung P.S. The Effects of Empagliflozin, an SGLT2 Inhibitor, on Pancreatic $\beta$-Cell Mass and Glucose Homeostasis in Type 1 Diabetes. PLoS One. 2016; 11(1): e0147391. doi: 10.1371/journal.pone.0147391.

43. Vallon, V., Gerasimova. M., Rose, M.A., Masuda, T., Satriano, J., Mayoux, E., Koepsell, H., Thomson, S.C., Rieg T. SGLT2 inhibitor empagliflozin reduces renal growth and albuminuria in proportion to hyperglycemia and prevents glomerular hyperfiltration in diabetic Akita mice. Am. J. Physiol. Renal Physiol. 2014; 306(2): F194 204. doi: 10.1152/ajprenal.00520.2013.

44. Skrtić, M., Yang. G.K., Perkins, B.A., Soleymanlou, N., Lytvyn, Y., von Eynatten, M., Woerle, H.J., Johansen, O.E., Broedl, U.C., Hach, T., Silverman, M., Cherney, D.Z. Characterisation of glomerular haemodynamic responses to SGLT2 inhibition in patients with type 1 diabetes and renal hyperfiltration. Diabetologia. 2014; 57: 2599 2602. doi: 10.1007/s00125-014-3396-4.

45. Navarro-González, J.F., Mora-Fernández, C. The role of inflammatory cytokines in diabetic nephropathy. J. Am. Soc.Nephrol. 2008; 19: 433 - 442. doi: 10.1681/ASN.2007091048.

46. Sharma, K., Jin, Y., Guo, J., Ziyadeh, F.N. Neutralization of TGF-beta by anti-TGF-beta antibody attenuates kidney hypertrophy and the enhanced extracellular matrix gene expression in STZ-induced diabetic mice. Diabetes. 1996. 45(4): 522 530. 
http://diabetes.diabetesjournals.org/content/45/

$4 / 522$.

47. Lim, A.K., Tesch, G.H. Inflammation in diabetic nephropathy. Mediators Inflamm. 2012; 2012: Article ID 146154, 12 pages. https://www.hindawi.com/journals/mi/2012/14 6154/

48. Gallo, L.A., Ward, M.S., Fotheringham, A.K., Zhuang, A., Koepsell, H., Vallon, V., Pollock, C., Panchapakesan, U., Forbes, J.M. The SGLT2 Inhibitor, Empagliflozin, Attenuates Some Markers of Renal Fibrosis without Improving Albuminuria in Diabetic Db/Db Mice. FASEB J. 2016; 30 (1): 740.18. https://doi.org/10.1096/fasebj.30.1_supplement. 740.18

49. Giacco, F., Brownlee, M. Oxidative stress and diabetic complications. Circ. Res. 2010; 107(9): $1058 \quad-\quad 1070 . \quad$ doi: 10.1161/CIRCRESAHA.110.223545.

50. Kashihara, N., Haruna, Y., Kondeti, V.K., Kanwar, Y.S. Oxidative stress in diabetic nephropathy. Curr. Med. Chem. 2010; 17(34): 4256 - 69. doi: 10.2174/092986710793348581.

51. van Dam, P.S., van Asbeck, B.S., Van Oirschot, J.F., Biessels, G.J., Hamers, F.P., Marx, J.J. Glutathione and alpha-lipoate in diabetic rats: nerve function, blood flow and oxidative state. Eur. J. Clin. Invest. 2001; 31(5):417 - 24. doi: 10.1046/j.13652362.2001.00832.x.

52. Jacheć, W., Tomasik, A., Tarnawski, R., Chwalińska, E. Evidence of oxidative stress in the renal cortex of diabetic rats: favourable effect of vitamin E. Scand. J. Clin. Lab. Invest. 2002; 62(1):81 - $8 . \quad$ doi: $10.1080 / 003655102753517244$.
53. Miranda-Díaz, A.G., Pazarín-Villaseñor, L., Yanowsky-Escatell, F.G., Andrade-Sierra, J. Oxidative Stress in Diabetic Nephropathy with Early Chronic Kidney Disease. J. Diabetes Res. 2016; 2016: 7047238 . doi: $10.1155 / 2016 / 7047238$.

54. Oelze, M., Kröller-Schön, S., Mader, M., Zinßius, E., Stamm, P., Hausding, M., Mayoux, E., Wenzel, P., Schulz, E., Münzel, T., Daiber, A. Effects of empagliflozin on oxidative stress and endothelial dysfunction in STZ-induced Type 1 diabetic rat. Diabetologie und Stoffwechsel. 2014; 9: 247 . doi: 10.1055/s-0034-1375104 